\title{
Epigenetic contributions to cognitive aging: disentangling mindspan and lifespan
}

\author{
Amy M. Spiegel, Angila S. Sewal, and Peter R. Rapp \\ Neurocognitive Aging Section, Laboratory of Behavioral Neuroscience, National Institute on Aging, Baltimore, Maryland 21224, USA
}

\begin{abstract}
Epigenetic modifications of chromatin structure provide a mechanistic interface for gene-environment interactions that impact the individualization of health trajectories across the lifespan. A growing body of research indicates that dysfunctional epigenetic regulation contributes to poor cognitive outcomes among aged populations. Here we review neuroepigenetic research as it relates to cognitive aging, focusing specifically on memory function mediated by the hippocampal system. Recent work that differentiates epigenetic contributions to chronological aging from influences on mindspan, or the preservation of normal cognitive abilities across the lifespan, is also highlighted. Together, current evidence indicates that while age-related memory impairment is associated with dysfunction in the coordinated regulation of chromatin modification, animal models that show individual differences in cognitive outcome underscore the enormous mechanistic complexity that surrounds epigenetic dynamics in the aged hippocampus.
\end{abstract}

Cognitive decline, especially memory loss, is one of the most prevalent and feared consequences of growing older. In the United States it is expected that by $2050, \sim 12 \%$ of people over the age of 65 will suffer from moderate-to-severe memory impairment (Federal Interagency Forum on Aging-Related Statistics: Older Americans Update 2004). Understanding the neural basis of cognitive decline is all the more pressing in light of national demographic trends highlighting the rapidly expanding elderly population, with the number of people aged 65 and older projected to increase from 43 million to more than 83 million over the next four decades (Ortman et al. 2014). Alongside a focus on negative outcomes, there is increasing recognition that memory decline is not an inevitable consequence of aging as some older adults maintain normal memory abilities across the lifespan. Identifying the neurobiological mechanisms that impact differential cognitive outcomes with age is critical. In this context, research exploring the biological substrates that drive individual healthspan trajectories from early development through old age can provide valuable insight into the brain mechanisms that influence mindspan.

A life course perspective emphasizes that environmental and experiential factors operate throughout life to potently influence the biological mechanisms that dictate the arc of an individual's health trajectory (for review, see Halfon et al. 2014). An emerging theme is that age alone is only a coarse predictor of health outcome, and current efforts are focused on disentangling chronological age effects from other determinants of functional outcomes in the elderly. Epigenetic modifications of the genome have gained attention in this context since they allow for genomic plasticity in post-mitotic cells and provide a means by which environment and experience interface with gene transcription to impact biological functions across the lifespan. This plasticity is crucial for adaptation and resilience in the face of environmental challenge, and when rendered dysfunctional, can negatively impact disease development and health. In addition to contributing to individual differences in healthspan, epigenetic modifications are candidate mechanisms for mediating variability in mindspan trajectories.

\section{Corresponding author: rappp@mail.nih.gov}

Article is online at http://www.learnmem.org/cgi/doi/10.1101//m.033506.113.
Mounting evidence indicates that epigenetic modifications of chromatin structure contribute to the experience-dependent synaptic plasticity in the hippocampus that underlies memory formation (Day and Sweatt 2011a,b; Sultan and Day 2011; Fischer 2014). Recent research also demonstrates that dysfunctional epigenetic regulation of experience-dependent gene transcription in the hippocampus is associated with memory impairment in aged rodents. Relatively few studies, however, have attempted to distinguish epigenetic alterations that are the consequence of chronological aging from changes that specifically influence differential cognitive outcomes.

Here we review neuroepigenetic research on age-related memory decline in rodent models with an emphasis on how current knowledge informs an understanding of mindspan and individual variability in cognitive trajectories. Topics addressed include how altered gene transcription profiles in the aged memory-impaired hippocampus are related to dysfunctional histone modifications, as well as data examining the therapeutic potential of pharmacological inhibitors of histone deacetylases for the treatment of age-related memory loss. In a final section we turn to the topic of cognitive resilience in aging and how adaptive epigenetic dynamics might contribute to memory preservation in some older individuals.

\section{Hippocampal gene transcription profiles in the aged brain}

Memory impairment in normal aging, meaning memory decline not associated with disease, is a conserved feature of growing older across invertebrates, rodents, monkeys, and humans (Gallagher and Rapp 1997; Erickson and Barnes 2003; Rosenzweig and Barnes 2003; Gallagher et al. 2006). However, unlike neurodegenerative disease that profoundly impacts memory (i.e., Alzheimer's disease), hippocampus-dependent memory deficits that emerge

This article is distributed exclusively by Cold Spring Harbor Laboratory Press for the first 12 months after the full-issue publication date (see http://learnmem. cshlp.org/site/misc/terms.xhtml). After 12 months, it is available under a Creative Commons License (Attribution-NonCommercial 4.0 International), as described at http://creativecommons.org/licenses/by-nc/4.0/. 
during normal aging can occur in the absence of massive neuronal death (West 1993; West et al. 1993; Rapp and Gallagher 1996; Rasmussen et al. 1996; Calhoun et al. 1998). Instead, subtle changes in the connectional and functional integrity of key hippocampal circuits appear to underlie memory impairment in older individuals (Barnes 1979; Barnes and McNaughton 1980; Geinisman et al. 1992; Barnes et al. 1997; Smith et al. 2000; Nicholson et al. 2004; Tombaugh et al. 2005; Wilson et al. 2005; Yassa et al. 2010, 2011; Hara et al. 2011, 2012a,b). Here we focus particularly on age-related changes in hippocampal gene transcription that negatively impact synaptic plasticity mechanisms known to be critical for normal memory.

Long-lasting hippocampal synaptic plasticity requires activity-dependent gene transcription and de novo protein synthesis, and disrupted regulation of these processes has negative effects on memory (Agranoff 1965; Davis and Squire 1984). In the context of aging, altered transcriptional regulation of genes that promote or are necessary for synaptic plasticity is associated with memory impairment in aged rodents (Blalock et al. 2003; Rowe et al. 2007; Haberman et al. 2011). Affected genes implicated in plasticity notably include the immediate-early genes HomerI1a, and Arc (activity regulated cytoskeleton-associated protein), which are necessary for learning and memory (Penner et al. 2011), as well as zif268, $b d n f$ (brain-derived neurotrophic factor) (Hattiangady et al. 2005), and reelin (Stranahan et al. 2011). Data derived from a rodent model of neurocognitive aging in which old Long-Evans rats show individual variability in cognitive outcome highlight the marked changes in hippocampal gene transcription that occur in association with age-related memory impairment, thereby distinguishing neurobiological signatures that are specifically associated with age-related memory decline from changes coupled with chronological age, unrelated to cognitive outcome. Adopting this approach, Haberman et al. (2011) demonstrated that aged rats with memory impairment show a constellation of gene transcriptional changes that are positioned to influence a wide range of learning and memory-related processes in the hippocampus. Affected targets include gene expression important for synaptic plasticity and connectivity, and protein quality control, a function necessary for neuronal health and memory consolidation (Haberman et al. 2011). Importantly, together these transcriptional alterations yield distinct profiles of hippocampal gene expression that clearly distinguish aged memory-impaired animals from both young rats and aged animals with preserved memory function. Although the neurobiological influences responsible for these changes are likely multifaceted, available evidence points to altered epigenetic regulation of chromatin structure as a potentially powerful drive on the host of gene transcriptional changes observed in the aged brain.

\section{Epigenetic contributions to learning and memory}

Accumulating data indicate that the epigenetic regulation of chromatin structure potently influences experience-dependent transcription of genes that support learning- and memory-related plasticity (Day and Sweatt 2011a,b; Gräff et al. 2011; Zovkic et al. 2013). Learning events induce dynamic epigenetic change in chromatin structure, modifying DNA accessibility for gene transcription, thereby linking the regulation of chromatin structure to experience-dependent gene transcription in the hippocampus. Histone acetylation and DNA methylation (discussed later in this review) are the two most widely studied epigenetic mechanisms in learning and memory research (for recent reviews, see Peixoto and Abel 2013; Zovkic et al. 2013). The following sections survey the current state of epigenetic research related to normal memory and age-related memory loss, focusing particular attention on re- cent evidence highlighting the complexity of histone modification dynamics in normal learning and memory function.

Nucleosomes comprise the fundamental unit of chromatin, formed by DNA tightly bound around an octamer of the core histone proteins H2A, H2B, H3, and H4 (Gräff and Tsai 2013a). Modifications to these histone proteins alter chromatin structure in ways that are more or less permissive for gene transcription. While a number of mechanisms are known to influence chromatin remodeling, histone acetylation is among the bestcharacterized post-translational modifications. The acetylation of histones by histone acetyltransferases (HATs) involves the transfer of acetyl groups to the amino-terminal lysine residues of histones. This transfer alters chromatin structure through the combined actions of direct chromatin remodeling and the recruitment of additional transcription factors. The opening of chromatin structure results in a chromatin state that is more permissive for gene transcription, including the transcription of genes necessary for learning- and memory-related plasticity (for review, see Sultan and Day 2011; Peixoto and Abel 2013; Zovkic et al. 2013).

Histone acetylation levels are modulated in the rodent hippocampus in response to training on a variety of learning and memory tasks, including spatial water maze procedures, objectplace recognition and contextual fear conditioning (Levenson et al. 2004; Oliveira et al. 2007; Vecsey et al. 2007; Bousiges et al. 2010; Peleg et al. 2010; Haettig et al. 2011; Castellano et al. 2012). In the case of contextual fear conditioning, for example, increased acetylation of histone $\mathrm{H} 3$ and $\mathrm{H} 4$ at multiple lysine sites, including H3K9, H3K14, H4K5, H4K8, and H4K12, has been reported in young $\mathrm{C} 57 \mathrm{BL} / 6$ mice following behavioral training (Peleg et al. 2010). Notably, these acetylation changes are associated with increased transcription of genes that are both important for memory and vulnerable in aging, including Fmn2 (formin 2), Prkca (protein kinase C, alpha), and Shank3 (also known as proline-rich synapse-associated protein 2). Control mice exposed to the same context in the absence of pairing with the fear conditioning shock fail to display increased histone acetylation, supporting the interpretation that the effects observed in trained animals are specifically associated with hippocampus-dependent memory.

\section{HDACs as pharmacological targets for memory enhancement}

Studies using pharmacological tools provide an additional, independent window on the role of histone acetylation in learning and memory. Pharmacological manipulations of histone acetylation in behavioral studies have predominantly targeted histone deacetylases (HDACs), which serve to reverse the histone acetylation process. In many cases, histone deacetylation condenses chromatin and represses gene transcription. Although many classes of HDAC enzymes have been identified, with distinct cell biological activities and influences on learning and memory, the most widely used pharmacological inhibitors target multiple HDACs (i.e., sodium butyrate, trichostatin A, suberoylanilide hydroxamic acid; SAHA, etc.) (Levenson et al. 2004; Guan et al. 2009; Peleg et al. 2010; Gräff et al. 2011; McQuown et al. 2011; Gräff and Tsai 2013b). Despite their broad specificity, HDAC inhibitors reportedly enhance electrophysiological signatures of hippocampal plasticity (i.e., long-term potentiation), and improve long-term memory when administered prior to learning (Levenson et al. 2004; Lattal et al. 2007).

Whereas early findings prompted the view that experiencedependent and pharmacologically induced increases in hippocampal histone acetylation reliably benefit memory, current evidence suggests a more nuanced picture. Castellano et al. (2014), 
for example, reported that, rather than uniformly increasing histone $\mathrm{H} 3$ and $\mathrm{H} 4$ acetylation, behavioral training in multiple animal models, including strains and testing procedures adopted from earlier work (Levenson et al. 2004; Peleg et al. 2010), led to modest decreases or no change in hippocampal histone acetylation. Indeed other work from the same group suggests that bidirectional and subregion-specific regulation of experience-dependent histone acetylation might contribute to the different pattern of results observed across studies (Castellano et al. 2012). In those experiments, levels of acetylated histone $\mathrm{H} 3$ and $\mathrm{H} 4$ following training in a redundant place-cue variant of the water maze varied across the principal cell fields of the hippocampus such that some modifications increased in a subset of regions but decreased or exhibited no change in others. Findings compatible with these observations were reported by Dagnas and Mons (2013), demonstrating increased $\mathrm{H} 3$ and $\mathrm{H} 4$ acetylation in the CA1 and DG of the hippocampus following spatial training, but no change in acetylation levels in the CA3 field. Pointing to a greater degree of circuit specificity than previously appreciated, these findings suggest that data derived from whole hippocampus homogenates may mask subtle, regionally selective changes in experiencedependent histone acetylation, contributing in part to the varied pattern of histone acetylation dynamics reported across studies.

The results of recent investigations using pharmacological manipulations have also prompted refinement in current perspectives on neuroepigenetic contributions to memory. For example, Castellano et al. (2014) reported that 24-h retention of fear memory is unaffected in young rats provided pretraining injection of a potent, brain penetrant HDAC inhibitor (i.e., EVX001688, FORUM Pharmaceuticals) that they directly confirmed yields robust increases in hippocampal histone acetylation at the time of fear conditioning. Negative results were also obtained with the more commonly used HDAC inhibitor, sodium butyrate, and indeed in this case there was a clear trend toward impaired memory with treatment. Our view is that variability in the reported effects of behavioral training and HDAC inhibitors on hippocampal histone acetylation dynamics and memory reflects gaps in our understanding of the full complexity by which epigenetic mechanisms mediate environmental influences on gene transcription important for memory-related synaptic plasticity. Despite the lack of a complete account, emerging evidence reviewed in the following sections suggests that epigenetic regulation may play a significant role in dictating individual differences in lifecourse cognitive trajectories.

\section{Epigenetic signatures of cognitive aging}

Although considerable interest surrounds the topic of epigenetic involvement in neurodegenerative disease, including Alzheimer's (for review, see Mastroeni et al. 2011; Stilling and Fischer 2011), relatively little attention has focused on directly identifying epigenetic markers of normal cognitive aging. In a uniquely comprehensive initial study in this area, Peleg et al. (2010) examined histone acetylation levels in the hippocampus of aged mice with memory deficits (at 16 mo of age). The findings revealed that age-related impairment in this model is selectively associated with decreased learning-induced histone acetylation at lysine 12 on histone H4 (H4K12) in the hippocampus. Reduced acetylation of H4K12 was also associated with blunted learning-induced hippocampal gene transcription. Remarkably, restoration of H4K12 acetylation levels with administration of the HDAC inhibitor SAHA broadly reinstated experience-dependent gene transcription and ameliorated the impaired fear memory observed in aged mice. Together these data point to a single, discrete epigenetic defect as a possible brain biomarker of cognitive aging, and provide evidence for the therapeutic potential of HDAC inhibitors in the treatment of age-related memory impairment. Administration of the HDAC inhibitor sodium butyrate also reportedly rescues age-related memory impairment assessed by a novel object recognition procedure in rats, further supporting the efficacy of HDAC inhibitors for cognitive decline in normal aging (Reolon et al. 2011).

While certain epigenetic changes are tightly correlated with chronological age (Horvath 2013), a focus on individual health trajectories and differential cognitive outcomes highlights the importance of distinguishing epigenetic alterations associated with chronological age from those specifically related to the integrity of memory function. Most of the research reviewed above, by comparison, provides insight into epigenetic changes that occur in the brains of aged animals with relatively homogenous cognitive outcomes. To address more directly how histone acetylation alterations contribute to preserved versus impaired memory with age, recent work has leveraged a well-characterized rat model of cognitive aging that exhibits reliable individual differences, ranging from aged individuals with memory comparable with normal young adults, to other aged rats that exhibit substantial deficits in hippocampal memory. In one study of this sort, Castellano et al. (2012) found an age-related increase in histone $\mathrm{H} 4$ acetylation across all subfields of the hippocampus in relation to chronological age, but few individual epigenetic marks linked to cognitive status among the aged cohorts. Although no single modification accounted for variability in cognitive aging, the overall pattern of results revealed that coordinated regulation across multiple chromatin modifications was highly predictive. Specifically, under both baseline and behaviorally activated conditions, levels of many histone acetylation marks in the hippocampus were reliably correlated with water maze performance in young rats and aged subjects with preserved memory. In contrast, performance in aged rats with impaired memory was entirely uncoupled from the status of the epigenetic modifications examined. A follow-up study taking advantage of this model examined the potential benefit of HDAC inhibitor administration, testing whether the marked increases in bulk hippocampal histone acetylation induced by pretraining injections of EVX001688 (EVX) are sufficient to rescue age-related impairment on a redundant placecue variant of the water maze (Castellano et al. 2014). Unlike the benefit reported in aged mice that were provided other compounds (Peleg et al. 2010), EVX had no effect on age-related memory deficits, despite confirmation that treatment induced robust increases in hippocampal histone acetylation at the time of learning. One way of understanding these results is that globally elevating histone acetylation fails to correct the disrupted orchestration of epigenetic dynamics seen in the hippocampus of aged animals with memory impairment (Castellano et al. 2012). The significant implication for therapeutic development is that more selective approaches, targeting coordinated control, may be needed to harness the potential of neuroepigenetic interventions for promoting healthy mindspan.

Alongside histone modifications, emerging data on changes in DNA methylation add to the complexity of potential epigenetic alterations in the aged brain that might contribute to memory decline (Liu et al. 2009). DNA methylation, i.e., the addition of a methyl group to a cytosine base within CpG dinucleotides, is mediated by DNA methyltransferase (DNMT) enzymes. This process creates a relatively stable covalent modification that is traditionally understood to repress gene transcription by promoting closed chromatin states through the recruitment of transcriptional repressors and limiting DNA accessibility to transcriptional machinery (Day and Sweatt 2010). While this description is generally applicable, recent evidence suggests that the consequences of DNA methylation on transcription can vary considerably depending on a variety of factors including CpG island locus (Chahrour 
et al. 2008; Brenet et al. 2011). The effects of aging are complex, with some evidence pointing to an age-related decrease in global DNA methylation (Wilson et al. 1987), together with increased methylation at $\mathrm{CpG}$ islands across multiple brain regions in humans (Hernandez et al. 2011). The enrichment of methylation at CpG sites tends to occur more frequently among functionally related gene transcripts, including gene classes that regulate DNA binding and transcription factors. This age-related aggregation of methylation might contribute to transcriptional abnormalities reported in the aged brain, and consistent with this possibility, altered methylation of Arc DNA in the CA1 field and dentate gyrus of the hippocampus in aged rats is associated with decreased Arc transcription and spatial memory impairment (Penner et al. 2011).

Additional evidence suggesting that DNA methylation influences differential cognitive outcomes in aging derives from a targeted study examining methylation in the promoter regions of Gabra5, Hspa5, and Syn1, i.e., genes previously implicated in age-related cognitive decline in the Long-Evans rat (Haberman et al. 2011). The overall results revealed an increase in the number of methylated sites across all three genes, but only in relation to chronological age, not cognitive status (Haberman et al. 2012). Higher resolution analysis, however, documented that methylation varied substantially across promoter CpGs on the Gabra5 gene, and reliably distinguished aged rats with memory impairment at one site. While only limited data are available pertaining to methylation changes in the aged rodent brain, a reasonable account of the observations reported by Haberman et al. (2011) is that methylation of individual CpGs within a transcription factor site may be more directly relevant to key memory-related cell biological processes than average methylation levels across promoter regions. By this view, deeper mapping of $\mathrm{CpG}$ island methylation across the genome may be necessary to accurately characterize how the dysregulation of epigenetic chromatin modification contributes to cognitive decline with age. Overall, the limited findings currently available highlight both the growing consensus for a potent epigenetic contribution to normal neurocognitive aging, and at the same time, that many significant gaps in our understanding remain. What is perhaps most clear is that a comprehensive epigenetic account, linking a life course history of environmental and experiential influences to the gene transcriptional alterations that mediate individual health and cognitive trajectories, is likely to reveal far greater complexity than the field has presumed.

\section{Epigenetic contributions to cognitive resilience with age}

The concept of cognitive resilience in aging has attracted considerable attention in human research. Brain-based theories of cognitive resilience include those that view resilience as cognitive reserve, which is influenced by the ability to process tasks more efficiently, as well as those that emphasize compensatory network mechanisms as the driving force behind successful aging (Stern 2002; Resnick and Sojkova 2011). Here we build on the concept of cognitive resilience and consider evidence for a somewhat different perspective, suggesting that preserved memory in aging reflects the recruitment of adaptive epigenetic dynamics in support of successful cognitive trajectories.

Data derived from research using the Long-Evans model of cognitive aging indicate that memory-impaired aged rats exhibit basal gene transcription profiles in the CA3 field of the hippocampus that distinguish them from their aged memory-intact counterparts (Haberman et al. 2011). Whereas the gene transcription changes observed in this study at baseline in aged-impaired ani- mals were discussed earlier, the noteworthy observation in the present context is that CA3 gene transcription profiles in this study also differentiated aged memory-intact rats from young rats, counting against the view that preserved memory in aging simply reflects the perpetuation of a youthful neuronal phenotype (Haberman et al. 2011). Findings from Haberman et al. (2013), examining behaviorally activated gene transcription profiles in the CA3 field of the hippocampus, also support the notion of active adaptive mechanisms as a basis for preserved memory function in aging. Specifically, while some behaviorally induced molecular pathways in the aged memory-unimpaired rat cohort overlapped with the young animals, a number of gene signatures differentiated aged-unimpaired animals from both aged-impaired and young rats. Interestingly, some of the gene signatures that were elevated following behavioral activation in aged rats with intact memory were originally observed to be in a repressed state under basal conditions compared with young and aged memoryimpaired animals (Haberman et al. 2011). Many of the genes exhibiting this profile are implicated in inhibitory network function in the hippocampus, a network that is compromised in the aged memory-impaired rat hippocampus, but preserved in aged subjects with normal memory (Spiegel et al. 2013). Thus, the ability to adaptively recruit transcriptional mechanisms in response to current environmental contingencies may contribute to the preservation of inhibitory network function and memory ability in aged rats with intact cognitive function.

It remains to be determined whether epigenetic chromatin modifications are among the mechanisms by which aged memory-unimpaired rats recruit adaptive transcriptional control. Castellano et al. (2012) observed that aged rats with intact memory exhibit decreased experience-dependent HDAC2 protein levels in the dentate gyrus compared with young and aged memory-impaired rats. The down-regulation of HDAC2 - an HDAC shown to negatively regulate memory-may reflect an adaptive epigenetic signature of successful aging that permits gene transcription required for normal memory function. Contrasted with the concept of cognitive reserve, this mechanism is neither a more efficient use of existing networks nor a compensatory response to network dysfunction. Instead, these data prompt the speculation that healthy cognitive aging might partly depend on the ability to flexibly recruit existing transcriptional machinery on demand to support normal cognitive function. The additional implication is that cognitive resilience may be mediated in the aged brain through epigenetic mechanisms that are amenable to pharmacological manipulation. Further work in this area might profitably focus on identifying epigenetic signatures of successful aging that can be targeted in treatments for age-related memory impairment.

\section{Concluding remarks}

The plasticity provided by epigenetic chromatin modifications is crucial for adaptation and resilience in the face of environmental adversity, and individual health trajectories can be negatively impacted when these mechanisms are disrupted. Here we reviewed data from the preclinical animal literature demonstrating how epigenetic alterations in the hippocampus can influence mindspan trajectories from impaired memory to resilience with age. The available research highlights that the epigenetic regulation of chromatin structure in the hippocampus is positioned to play a central role in the altered gene transcription profiles associated with both impaired and preserved memory in aging. Establishing a comprehensive account of the brain mechanisms that dictate differential life course trajectories of mindspan, and that promote resilient, adaptive outcomes, is a critical unmet challenge as we approach an era of individualized healthcare. 


\section{Acknowledgments}

We thank Lisa Taxier for editorial input and members of the Neurocognitive Aging Section for helpful discussion. This work was supported by the Intramural Research Program of the National Institute on Aging.

\section{References}

Agranoff BW. 1965. Molecules and memories. Perspect Biol Med 9: 13-22.

Barnes CA. 1979. Memory deficits associated with senescence: a neurophysiological and behavioral study in the rat. J Comp Physiol Psychol 93: 74-104.

Barnes CA, McNaughton BL. 1980. Physiological compensation for loss of afferent synapses in rat hippocampal granule cells during senescence. J Physiol 309: 473-485.

Barnes CA, Rao G, Shen J. 1997. Age-related decrease in the N-methyl-DaspartateR-mediated excitatory postsynaptic potential in hippocampal region CA1. Neurobiol Aging 18: 445-452.

Blalock EM, Chen KC, Sharrow K, Herman JP, Porter NM, Foster TC, Landfield PW. 2003. Gene microarrays in hippocampal aging. Statistical profiling identifies novel processes correlated with cognitive impairment. J Neurosci 23: 3807-3819.

Bousiges O, Vasconcelos AP, Neidl R, Cosquer B, Herbeaux K, Panteleeva I, Loeffler JP, Cassel JC, Boutillier AL. 2010. Spatial memory consolidation is associated with induction of several lysine-acetyltransferase (histone acetyltransferase) expression levels and $\mathrm{H} 2 \mathrm{~B} / \mathrm{H} 4$ acetylationdependent transcriptional events in the rat hippocampus. Neuropsychopharmacology 35: 2521-2537.

Brenet F, Moh M, Funk R, Feierstein E, Viale AJ, Socci ND, Scandura JM. 2011. DNA methylation of the first exon is tightly linked to transcriptional silencing. PLoS One 6: e14524.

Calhoun ME, Kurth D, Phinney AL, Long JM, Hengemihle J, Mouton PR, Ingram DK, Jucker M. 1998. Hippocampal neuron and synaptophysinpositive bouton number in aging C57BL/6 mice. Neurobiol Aging 19: 599-606.

Castellano JF, Fletcher BR, Kelley-Bell B, Kim DH, Gallagher M, Rapp PR. 2012. Age-related memory impairment is associated with disrupted multivariate epigenetic coordination in the hippocampus. PLoS One 7: e33249.

Castellano JF, Fletcher BR, Patzke H, Long JM, Sewal A, Kim DH, Kelley-Bell B, Rapp PR. 2014. Reassessing the effects of histone deacetylase inhibitors on hippocampal memory and cognitive aging. Hippocampus 24: 1006-1016.

Chahrour M, Jung SY, Shaw C, Zhou X, Wong ST, Qin J, Zoghbi HY. 2008 $\mathrm{MeCP} 2$, a key contributor to neurological disease, activates and represses transcription. Science 320: $1224-1229$.

Dagnas M, Mons N. 2013. Region- and age-specific patterns of histone acetylation related to spatial and cued learning in the water maze. Hippocampus 23: 581-591.

Davis HP, Squire LR. 1984. Protein synthesis and memory: a review. Psychol Bull 96: $518-559$

Day JJ, Sweatt JD. 2010. DNA methylation and memory formation. Nat Neurosci 13: 1319-1323.

Day JJ, Sweatt JD. 2011a. Cognitive neuroepigenetics: a role for epigenetic mechanisms in learning and memory. Learn Mem 96: 2-12.

Day JJ, Sweatt JD. 2011b. Epigenetic mechanisms in cognition. Neuron 70: $813-829$.

Erickson CA, Barnes CA. 2003. The neurobiology of memory changes in normal aging. Exp Gerontol 38: 61-69.

Federal Interagency Forum on Aging-Related Statistics. 2004. Older Americans 2004: key indicators of well-being. Federal Interagency Forum on Aging-Related Statistics. US Government Printing Office, Washington, DC.

Fischer A. 2014. Epigenetic memory: the Lamarckian brain. EMBO J 33: $945-967$.

Gallagher M, Rapp PR. 1997. The use of animal models to study the effects of aging on cognition. Annu Rev Psychol 48: 339-370.

Gallagher M, Colantuoni C, Eichenbaum H, Haberman RP, Rapp PR, Tanila H, Wilson IA. 2006. Individual differences in neurocognitive aging of the medial temporal lobe. Age 28: 221-233.

Geinisman Y, deToledo-Morrell L, Morrell F, Persina IS, Rossi M. 1992. Age-related loss of axospinous synapses formed by two afferent systems in the rat dentate gyrus as revealed by the unbiased stereological dissector technique. Hippocampus 2: 437-444.

Gräff J, Tsai LH. 2013a. Histone acetylation: molecular mnemonics on the chromatin. Nat Rev Neurosci 14: 97-111.

Gräff J, Tsai LH. 2013b. The potential of HDAC inhibitors as cognitive enhancers. Annu Rev Pharmacol Toxicol 53: 311-330.

Gräff J, Kim D, Dobbin MM, Tsai LH. 2011. Epigenetic regulation of gene expression in physiological and pathological brain processes. Physiol Rev 91: 603-649.
Guan JS, Haggarty SJ, Giacometti E, Dannenberg JH, Joseph N, Gao J, Nieland TJ, Zhou Y, Wang X, Mazitschek R, et al. 2009. HDAC2 negatively regulates memory formation and synaptic plasticity. Nature 459: $55-60$.

Haberman RP, Colantuoni C, Stocker AM, Schmidt AC, Pedersen JT, Gallagher M. 2011. Prominent hippocampal CA3 gene expression profile in neurocognitive aging. Neurobiol Aging 32: 1678-1692.

Haberman RP, Quigley CK, Gallagher M. 2012. Characterization of CpG island DNA methylation of impairment-related genes in a rat model of cognitive aging. Epigenetics 7: 1008-1019.

Haberman RP, Colantuoni C, Koh MT, Gallagher M. 2013. Behaviorally activated mRNA expression profiles produce signatures of learning and enhanced inhibition in aged rats with preserved memory. PLoS One 8: e83674.

Haettig J, Stefanko DP, Multani ML, Figueroa DX, McQuown SC, Wood MA. 2011. HDAC inhibition modulates hippocampus-dependent long-term memory for object location in a CBP-dependent manner. Learn Mem 18: $71-79$.

Halfon N, Larson K, Lu M, Tullis E, Russ S. 2014. Lifecourse health development: past, present and future. Matern Child Health J 18: 344-365.

Hara Y, Park CS, Janssen WG, Punsoni M, Rapp PR, Morrison JH. 2011. Synaptic characteristics of the dentate gyrus axonal boutons and their relationships with aging, menopause, and memory in female rhesus monkeys. I Neurosci 31: 7737-7744.

Hara Y, Punsoni M, Yuk F, Park CS, Janssen WG, Rapp PR, Morrison JH. 2012a. Synaptic distributions of GluA2 and PKM $\zeta$ in the monkey dentate gyrus and their relationships with aging and memory. J Neurosci 32: 7336-7744.

Hara Y, Rapp PR, Morrison JH. 2012b. Neuronal and morphological bases of cognitive decline in aged rhesus monkeys. Age 34: 1051-1073.

Hattiangady B, Rao MS, Shetty GA, Shetty AK. 2005. Brain-derived neurotrophic factor, phosphorylated cyclic AMP response element binding protein and neuropeptide $\mathrm{Y}$ decline as early as middle age in the dentate gyrus and CA1 and CA3 subfields of the hippocampus. Exp Neurol 195: 353-371.

Hernandez DG, Nalls MA, Gibbs JR, Arepalli S, van der Brug M, Chong S, Moore M, Longo DL, Cookson MR, Traynor BJ, et al. 2011. Distinct DNA methylation changes highly correlated with chronological age in the human brain. Hum Mol Genet 20: 1164-1172.

Horvath S. 2013. DNA methylation age of human tissues and cell types. Genome Biol 14: R115.

Lattal KM, Barrett RM, Wood MA. 2007. Systemic or intrahippocampal delivery of histone deacetylase inhibitors facilitates fear extinction. Behav Neurosci 121: 1125-1131.

Levenson JM, O'Riordan KJ, Brown KD, Trinh MA, Molfese DL, Sweatt JD. 2004. Regulation of histone acetylation during memory formation in the hippocampus. J Biol Chem 279: 40545-40559.

Liu L, van Groen T, Kadish I, Tollefsbol TO. 2009. DNA methylation impacts on learning and memory in aging. Neurobiol Aging 30: 549-560.

Mastroeni D, Grover A, Delvaux E, Whiteside C, Coleman PD, Rogers J. 2011. Epigenetic mechanisms in Alzheimer's disease. Neurobiol Aging 32: $1161-1180$.

McQuown SC, Barrett RM, Matheos DP, Post RJ, Rogge GA, Alenghat T, Mullican SE, Jones S, Rusche JR, Lazar MA, et al. 2011. HDAC3 is a critical negative regulator of long-term memory formation. J Neurosci 31: 764-774.

Nicholson DA, Yoshida R, Berry RW, Gallagher M, Geinisman Y. 2004. Reduction in size of perforated postsynaptic densities in hippocampal axospinous synapses and age-related spatial learning impairments. J Neurosci 24: 7648-7653.

Oliveira AM, Wood MA, McDonough CB, Abel T. 2007. Transgenic mice expressing an inhibitory truncated form of p300 exhibit long-term memory deficits. Learn Mem 14: 564-572.

Ortman JM, Velkoff VA, Hogan H. 2014. United States Department of Commerce. An aging nation: the older population in the United States. Economics and Statistics Administration, U.S. Census Bureau, Washington, DC.

Peixoto L, Abel T. 2013. The role of histone acetylation in memory formation and cognitive impairments. Neuropsychopharmacology 38: $62-76$

Peleg S, Sananbenesi F, Zovoilis A, Burkhardt S, Bahari-Javan S, Agis-Balboa RC, Cota P, Wittnam JL, Gogol-Doering A, Opitz L, et al. 2010. Altered histone acetylation is associated with age-dependent memory impairment in mice. Science 328: 753-756.

Penner MR, Roth TL, Chawla MK, Hoang LT, Roth ED, Lubin FD, Sweatt JD, Worley PF, Barnes CA. 2011. Age-related changes in Arc transcription and DNA methylation within the hippocampus. Neurobiol Aging 32: $2198-2210$.

Rapp PR, Gallagher M. 1996. Preserved neuron number in the hippocampus of aged rats with spatial learning deficits. Proc Natl Acad Sci 93: 9926-9930. 
Rasmussen T, Schliemann T, Sorensen JC, Zimmer J, West MJ. 1996. Memory impaired aged rats: no loss of principal hippocampal and subicular neurons. Neurobiol Aging 17: 143-147.

Reolon GK, Maurmann N, Werenicz A, Garcia VA, Schroder N, Wood MA, Roesler R. 2011. Posttraining systemic administration of the histone deacetylase inhibitor sodium butyrate ameliorates aging-related memory decline in rats. Behav Brain Res 221: 329-332.

Resnick SM, Sojkova J. 2011. Amyloid imaging and memory change for prediction of cognitive impairment. Alzheimers Res Ther 3: 3 .

Rosenzweig E, Barnes CA. 2003. Impact of aging on hippocampal function: plasticity, network dynamics, and cognition. Prog Neurobiol 69: $143-179$.

Rowe WB, Blalock EM, Chen KC, Kadish I, Wang D, Barrett JE, Thibault O, Porter NM, Rose GM, Landfield PW. 2007. Hippocampal expression analyses reveal selective association of immediate-early, neuroenergetic, and myelinogenic pathways with cognitive impairment in aged rats. I Neurosci 27: 3098-3110.

Smith TD, Adams MM, Gallagher M, Morrison JH, Rapp PR. 2000. Circuit-specific alterations in hippocampal synaptophysin immunoreactivity predict spatial learning impairment in aged rats. J Neurosci 20: 6587-6593.

Spiegel AM, Koh MT, Vogt NM, Rapp PR, Gallagher M. 2013. Hilar interneuron vulnerability distinguishes aged rats with memory impairment. J Comp Neurol 521: 3508-3523.

Stern Y. 2002. What is cognitive reserve? Theory and research application of the reserve concept. J Int Neuropsychol Soc 8: 448-460.

Stilling RM, Fischer A. 2011. The role of histone acetylation in age-associated memory impairment and Alzheimer's disease. Neurobiol Learn Mem 96: 19-26.

Stranahan AM, Haberman RP, Gallagher M. 2011. Cognitive decline is associated with reduced reelin expression in the entorhinal cortex of aged rats. Cereb Cortex 21: 392-400.
Sultan FA, Day JJ. 2011. Epigenetic mechanisms in memory and synaptic function. Epigenomics 3: 157-181.

Tombaugh GC, Rowe WB, Rose GM. 2005. The slow after hyperpolarization in hippocampal CA1 neurons covaries with spatial learning ability in aged Fisher 344 rats. J Neurosci 25: 2609-2616.

Vecsey CG, Hawk JD, Lattal KM, Stein JM, Fabian SA, Attner MA, Cabrera SM, McDonough CB, Brindle PK, Abel T, et al. 2007. Histone deacetylase inhibitors enhance memory and synaptic plasticity via CREB:CBP-dependent transcriptional activation. J Neurosci 27: 6128-6140.

West MJ. 1993. Regionally specific loss of neurons in the aging human hippocampus. Neurobiol Aging 14: 287-293.

West MJ, Amaral DG, Rapp PR. 1993. Preserved hippocampal cell number in aged monkeys with recognition memory deficits. Soc Neurosci Abstr 19: 599.

Wilson VL, Smith RA, Ma S, Cutler RG. 1987. Genomic 5-methyldeoxycytidine decreases with age. J Biol Chem 262: 9948-9951.

Wilson IA, Ikonen S, Gallagher M, Eichenbaum H, Tanila H. 2005. Age-associated alterations of hippocampal place cells are subregion specific. J Neurosci 25: 6877-6886.

Yassa MA, Muftuler LT, Stark CE. 2010. Ultrahigh-resolution microstructural diffusion tensor imaging reveals perforant path degradation in aged humans in vivo. Proc Natl Acad Sci 107: 12687-12691.

Yassa MA, Lacy JW, Stark SM, Albert MS, Gallagher M, Stark CE. 2011. Pattern separation deficits associated with increased hippocampal CA3 and dentate gyrus activity in nondemented older adults. Hippocampus 21: $968-979$.

Zovkic IB, Guzman-Karlsson MC, Sweatt JD. 2013. Epigenetic regulation of memory formation and maintenance. Learn Mem 20: 61-74.

Received June 3, 2014; accepted in revised form July 29, 2014. 


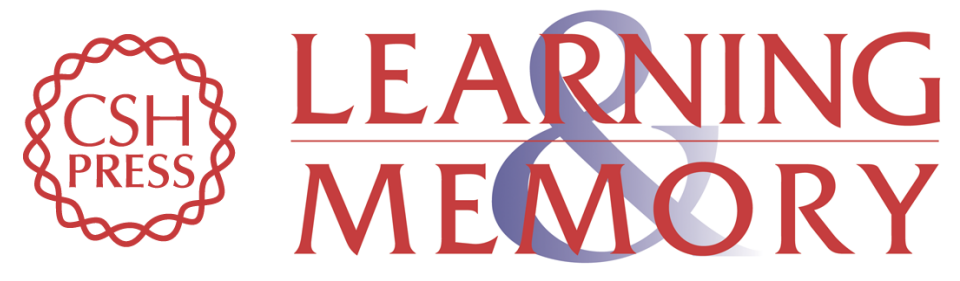

\section{Epigenetic contributions to cognitive aging: disentangling mindspan and lifespan}

Amy M. Spiegel, Angila S. Sewal and Peter R. Rapp

Learn. Mem. 2014, 21:

Access the most recent version at doi:10.1101/Im.033506.113

References This article cites 67 articles, 20 of which can be accessed free at: http://learnmem.cshlp.org/content/21/10/569.full.html\#ref-list-1

Creative This article is distributed exclusively by Cold Spring Harbor Laboratory Press for the Commons License first 12 months after the full-issue publication date (see

http://learnmem.cshlp.org/site/misc/terms.xhtml). After 12 months, it is available under a Creative Commons License (Attribution-NonCommercial 4.0 International), as described at http://creativecommons.org/licenses/by-nc/4.0/.

Email Alerting Receive free email alerts when new articles cite this article - sign up in the box at the Service top right corner of the article or click here. 